\title{
SCHEDULING MODEL FOR MULTIPLE DESIGN PROJECTS CONSIDERING UNCERTAIN DESIGN ITERATIONS
}

\author{
Wei-Chih Wang \\ Professor \\ Department of Civil Engineering \\ National Chiao Tung University \\ Hsin-Chu, Taiwan \\ weichih@mail.nctu.edu.tw
}

\author{
Jang-Jeng Liu \\ Graduate student \\ Department of Civil Engineering \\ National Chiao Tung University \\ Hsin-Chu, Taiwan \\ sandro.cv88g@nctu.edu.tw
}

\begin{abstract}
Although slightly improving the control of the design schedule may greatly reduce the total duration of the project, but little effort has been made to control the schedule of the design project. Scheduling design activities is complicated chiefly because the design activities often have different degrees of information dependencies between each other. That is, design process involves a number of iterations. This work develops a simulation-based model to incorporate uncertain design iterations for generating the schedule of multiple design projects for a design firm. The proposed model is implemented and demonstrated by a case study.
\end{abstract}

\section{KEYWORDS}

Uncertain Design Iteration, Simulation, Design Schedule, and Design Process.

\section{INTRODUCTION}

A design firm often needs to allocate various types of design participants (such as architects, designers and draftsmen) to the multi-disciplinary activities of various design projects that are in various project stages (such as the proposal, conceptual / schematic design, detailed design, and construction stages). Effectively assigning the design participants depends on how the design activities are scheduled.

Scheduling of design activities for multiple projects is complex because design activities frequently depend differently on information about each other. Namely, the design process involves various iterations across activities [1-6]. Moreover, the fact that the numbers of iterations and the durations of design activities are uncertain makes difficult to identify the precedence relationships among activities and to evaluate the durations of the design projects. This study develops a simulation-based scheduling model to effectively allocate design participants for multiple design projects. Particularly, simulation algorithms are proposed to model the uncertainties of design iterations and activity durations.

\section{PAST RESEARCH}

During the conceptual and schematic design stages of a building project, a chief designer (architect / engineer or $\mathrm{A} / \mathrm{E}$ ) gathers information from a wide range of disciplines; candidate solutions are proposed, and new states are generated from the current ones based on the information available to meet the owner's requirements, including, for example, the budget and general spatial arrangements $[4,7]$. These two early stages ensure that the design deliverables fulfill the owner's demands.

In the detailed design stage, the required design work is stated in greater details; the design deliverables must be delivered to prevent future construction work from being delayed. Much research has been done to improve the control of the detailed design process, increasing the effectiveness of the control of the design duration. For example, Sanvido and Norton proposed a 
building design process model that specified the keys for a successful design [8].

Steward considered design iterations and defined possible relationships between a pair of design activities - dependent, independent (parallel) and interdependent (coupled) [9]. Austin et al. elucidated a planning methodology (Analytical Design Planning Technique; ADePT) for planning building design [1-3].

Wang and Dzeng applied a modified cluster identification algorithm to evaluate the dependencies of design activities on information, to enable activities to be regrouped to support the assignment of design activities [10]. Wang et al. presented causes and various types of design iterations for a building project and developed an innovative simulation- based model to incorporate the design iterations to generate a schedule for a design project [6]. Finally, Cho and Eppinger proposed a DSM-based process model using simulation for managing industrial design projects [5].

\section{PROPOSED MODEL}

The proposed model extends a previous study of Wang et al. [6] to deal with multiple design projects, to incorporate the uncertainties of design iterations and the uncertainties of activity durations, and to offer a cost analysis. The model, developed from the perspective of a design firm, includes four major phases (Fig. 1)

\subsection{Phase I: Representing the Design Process for Multiple Projects}

A common design activity usually has deliverables such as drawings, reports, and calculations. For instance, the design activities considered herein include floor plan design and exterior elevation design activities, with the deliverables "plans" and "elevations", respectively. Another type of design activity, called review/approval activity herein, does not have definite outputs and it involves in certain amount of discussions, clarifications and even revisions. A design dependency is the logical relationship between activities. The dependency between activities, $\mathrm{A} \rightarrow \mathrm{B}$, demonstrates that the information flow delivers the design deliverables from $\mathrm{A}$ to $\mathrm{B}$.

Based on the identified activities and their dependencies, dependency structure matrix (DSM) is applied to help identify design iterations with complete loops. Steward [9] and many other publications provide details on the DSM methods. After iterations with complete loops have been found, the model user must explore whether incomplete design loops are present, based on past experience.

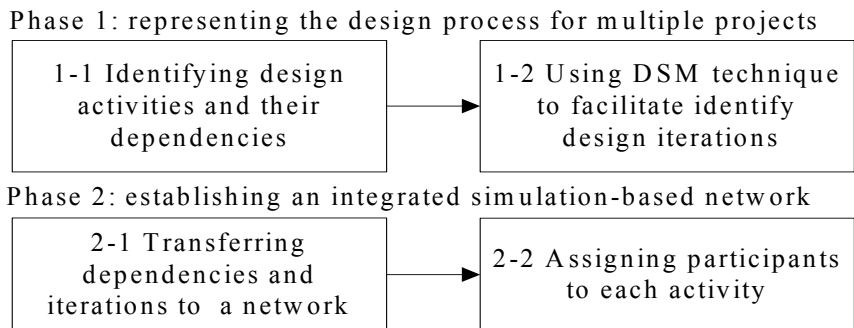

Phase 3 : deriving input parameters for computing durations and costs

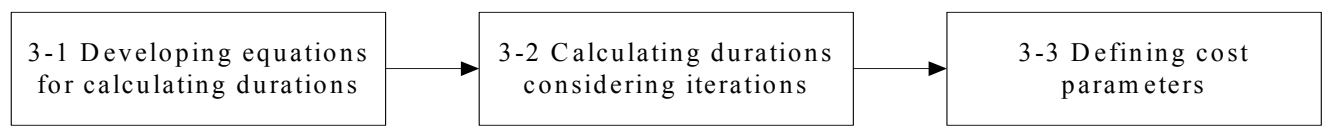

Phase 4: incorporating the uncertainties

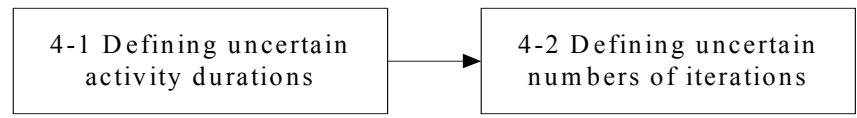

Figure 1 Proposed Model 


\subsection{Phase II: Establishing an Integrated Simulation-Based Network}

Phase I identifies dependencies and iterations. Phase II establishes a simulation-based network, and assigns design participants (such as architects, designers and assistant designers) to each activity. The proposed model uses the symbols of Stroboscope [161 to represent the simulation-based network of schedule. In Stroboscope, "Combi" nodes refer to design activities that start when specific conditions are met. Each Combi node is shown with a cut at the top left-hand corner of a square box. Queue nodes hold idle design resources. Each queue (indicated by a "Q" in the network) is related to a particular class of resource. A link $(\rightarrow)$ connects two network nodes and presents the direction and type of design resources that flow through them. The node at the tail of the link is the predecessor, and that at the head (indicated by the arrow) is the successor.

This step, assigning participants to each activity, is to allocate the type and the number of participants to each activity.

\subsection{Phase III: Deriving Input Parameters for Computing Durations and Costs}

The first step of phase 3 is developing equations for calculating durations. Regarding the computations of the durations of design activities, two methods are proposed. The first method is developed to handle the common design activities that produce design deliverables, and the second method is to deal with the review/ approval activities that have no explicit design deliverables.

The second step of phase 3 is calculating durations considering iterations. The time required to complete a design activity $i\left(D_{i(n)}\right)$ with $n$ iterations, is the sum of three parts - the time $\left(d_{i}\right)$ required to complete the amount of deliverables, the time $\left(d d_{i}\right)$ required to process the received and the to-be-delivered deliverables, and the time $\left(\sum_{n=1}^{N}\right.$ Iter $\left._{i(n)}\right)$ required to rework drawings due to iterations.

The third step of phase 3 is defining cost parameters. The proposed model offers a cost analysis by assigning wage rates (dollar per hour) to participants. The cost per participant equals the period of his or her participation (working and idle hours) multiplied by his wage rate. The total design costs are the sum of the participant costs. A design manager can thus make an improved decision in allocating design participants to activities, to ensure satisfactory project duration and cost.

\subsection{Phase IV: Incorporating the Uncertainties}

The first step of phase is defining uncertain activity durations. In computing the duration of activity $i$ (i.e., $\left.\left(D_{i(0)}\right)\right)$, the quantity of required deliverables $\left(Q_{i}\right)$ is assumed to be certain. However, the value of design productivity ( $P_{i j}$, hour per unit) is assumed to be probabilistic. The proposed model uses three-point estimates (optimistic, most likely, and pessimistic unit rates) to obtain a Beta distribution for the productivity for each participant $\mathrm{j}$ in each activity $i$. Notably, various participants with different degrees of productivity are involved in completing the drawings of an activity.

The second step of phase 4 is defining uncertain numbers of iterations. In the design process, a certain amount of design information may flow among activities several times until design deliverables are compatible or regulatory requirements are met. Whether an iteration with a complete or incomplete loop will arise is assumed to be probabilistic. The model also applies three-point estimates (lowest, most likely, and highest probabilities; between 0 and 1) to obtain a Beta distribution for the occurrence of an iteration loop $x$. A random variable $\left(\right.$ Occur $\left._{x}\right)$ for each iteration loop is devised. For example, the model user may specify that the lowest, most likely, and highest probabilities for the occurrence of an iteration loop $x$ are $0.2,0.4$, and 0.6 , respectively. Then, in each simulation run, a value will be drawn from the distribution $(0.2,0.4,0.6)$ to represent the probability that iteration loop $x$ will occur.

Additionally, the value of IterDR $R_{i}$ (the fraction of the developed drawings associated with activity $i$ that must be reworked at an iteration) is also treated as an uncertain variable. Again, the model utilizes three-point estimates (lowest, most likely, and highest fractions; between 0 and $100 \%$ ) to obtain a 
Beta distribution for indicating the fraction (or percentage) of IterDR . $_{\text {. }}$

\section{IMPLEMENTATION}

A simulation language, Stroboscope [11], is adopted to implement the simulation-related algorithms in the proposed model. All the abovementioned input parameters and derived equations must be suitably coded using Stroboscope statements. In this investigation, Stroboscope was run in the Windows XP environment, with a P3 $850 \mathrm{CPU}$ and 256 Mbytes of RAM. Five thousand simulations runs took under one minute for the case study.

\section{EXAMPLE}

\subsection{Project Description}

A medium-size architectural design firm that is located in northern Taiwan is used for demonstrating the proposed model. This firm must handle six design projects in two months (i.e., about 480 working hours). These design projects are related to $10 \sim 12$-floor office buildings. Projects $\mathrm{A}, \mathrm{B}$ and $\mathrm{F}$ are in construction phase and require certain design work caused by owner-directed change orders. Project C, D and E are in the construction tendering phase, conceptual design phase, and detailed design phase, respectively. Notably, the design work of these six projects involves four design disciplines - architectural, structural, HVAC and electrical.

\subsection{Inputs}

First, the design activities and their dependencies must be identified (Step 1-2). 79 activities are indicated in six projects. There are 1, 1, $10(8$ common activities and 2 review/approval activities), 30 (26 common activities and 4 review/approval activities), 34 (29 common activities and 5 review/approval activities), and 3 activities (2 common activities and 1 review/approval activity) are identified for projects A, B, C, D, E, and F, respectively. Four different disciplines perform these 79 activities.
The input data for structural, HVAC, and electrical design can also be provided in a similar manner. (These data are not displayed here due to the limitation of paper length.) Additionally, nine design participants are assumed to work on these projects. Table 1 displays the number and wage rate (US dollars per person per hour) for each participant. (Step 3-3).

\subsection{Evaluations}

Based on the identified precedence relationships between activities, the DSM is applied to search for iterations with a complete loop (Step 1-3). For example, Figure 2 presents the partitioned matrix for project E. Each " $\mathrm{X}$ " in the matrix indicates that the activity on the left-hand side depends on the activity at the top of the matrix. This partitioned matrix demonstrates that 34 activities of project $\mathrm{E}$ contribute to three iterative loops (iterations R, Y, and $\mathrm{U}$ with complete loops).

There are eight iterations (iterations $\mathrm{R}, \mathrm{S}, \mathrm{T}, \mathrm{U}, \mathrm{V}$, $\mathrm{W}, \mathrm{Y}$, and $\mathrm{Z})$ in the six projects. Six iterations (R, $\mathrm{S}, \mathrm{T}, \mathrm{U}, \mathrm{Y}$, and $\mathrm{Z}$ ) with complete loops are identified by DSM, while two iterations (V and $\mathrm{W}$ ) with incomplete loops are indicated by the model user.

\section{Table 1 Number of Persons and Wage Rate of Each Design Participant}

\begin{tabular}{lcc}
\hline \multicolumn{1}{c}{ Participants } & $\begin{array}{c}\text { Number of } \\
\text { persons }\end{array}$ & $\begin{array}{c}\text { Wage rate } \\
\text { (\$US / hour - person) }\end{array}$ \\
\hline Architectural discipline & & 50 \\
Architect & 1 & 30 \\
Designer & 1 & 23 \\
Draftsman & 1 & \\
$\quad$ Structural discipline & & 40 \\
Structural consultant & 1 & 26 \\
Structural engineer & 1 & 38 \\
$\quad$ HVAC discipline & & 25 \\
HVAC consultant & 1 & \\
HVAC engineer & 1 & 36 \\
$\quad$ Electrical discipline & & 28 \\
Electrical consultant & 1 & \\
Electrical engineer & 1 & \\
\hline
\end{tabular}




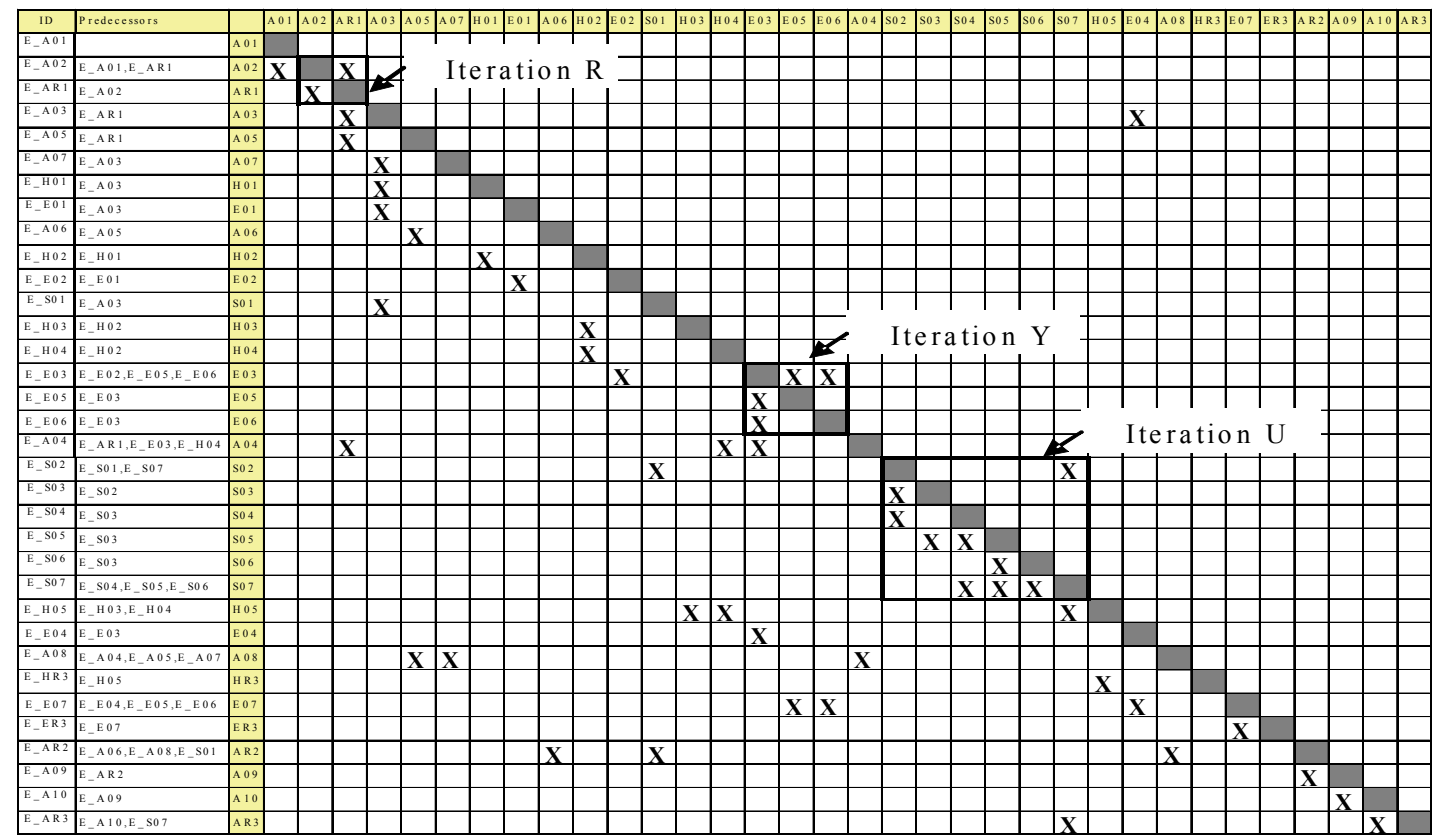

Figure 2 Three Iterations Identified by DSM in Project E

Figure 3 depicts the established simulation-based network for the six design project (Step 2-1). The network incorporates the 79 activities (represented by Combi nodes), 9 participants (represented by Queue nodes) and the dependencies among activities (represented by links). Additionally, eight Dynafork nodes (each represented by a cycle enclosing five rays) that have routing capabilities for activating downstream activities control the occurrence of the eight iterations. All small Queues shown in the network are used only to control the resource flows.

\subsection{Results}

By assuming that one of each type of participant is present and simulation is run for 5,000 times, the duration of the design work of six projects is 466.6 hours (approximately 58.3 working days, eight hours per day).

The simulation enables the model to evaluate the utilization rates of the participants (stored in Queues). That is, the working time, idle time, total cost and idle cost of each design participant involved in the six projects can be calculated. For instance, the idle times of the architect, the designer and the draftsman in performing the architectural activities are 257.0, 76.7 and 165.3 hours, respectively. Thus, a design manager may assign additional design activities (of the same project or other projects) to the architect who is very idle.

Finally, comparing with the scenarios with and without iterations, the consideration of iteration has increased the expected duration from 426.3 to 466.6 hours. The increase is about 40.3 hours $(=466.6-426.3) \quad$ or $\quad 9.5 \% \quad(=40.3 / 426.3)$. Additionally, using the 2 months (480 hours) as the deadline, the probability of meeting that deadline is about $66.4 \%$ (considering iterations).

\section{CONCLUSION}

This work devises a new model to generate schedules for multiple design projects. With the support of simulation technique, the model also considers the uncertainties on the durations of design activities and the occurrences of iterations for evaluating the risk of completion durations of design projects. Moreover, cost information with respect to different project durations can allow a trade-off analysis between the cost and time. 


\section{ACKNOWLEDGMENT}

The authors thank the National Science Council of Taiwan for financially supporting this research under Contract No. NSC95-2211-E-009- 244.

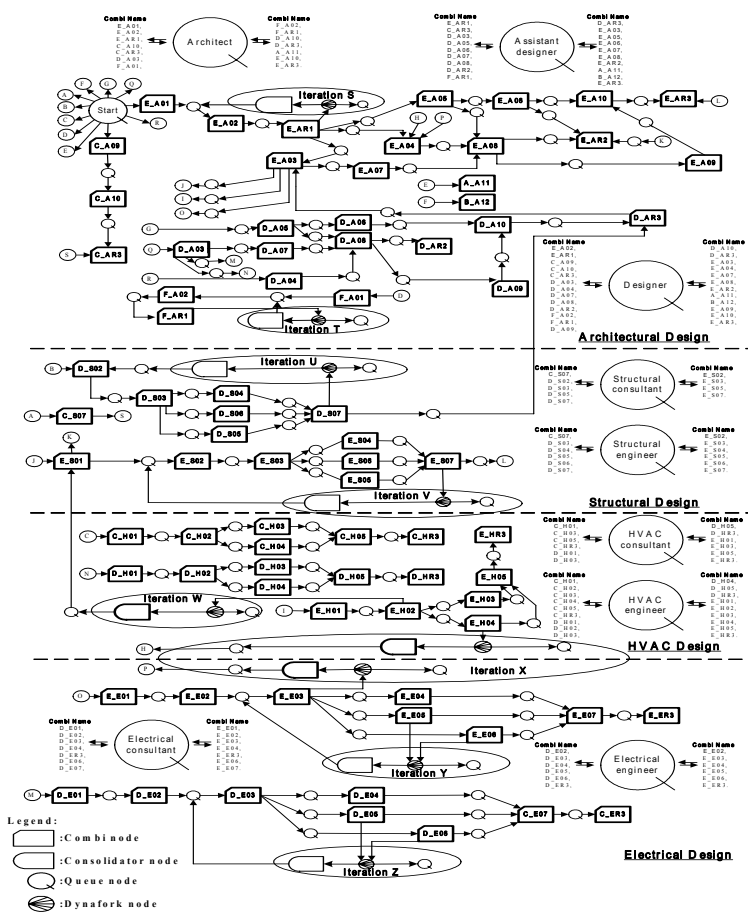

Figure 3 Simulation-Based Network of the Six Projects

\section{REFERENCES}

[1] Austin, S. Baldwin, A. Newton, A. (1994) Manipulating the flow of design information to improve the programming of building design, Construction Management and Economics, Vol. 12, 445-455.

[2] Austin, S. Baldwin, A. Li, B. Waskett, P. (1999) Analytical design planning technique: a model of the detailed building design process, Design Studies, Vol. 20, 279-296.

[3] Austin, S. Baldwin, A. Li, B. Waskett, P. (2000) Analytical design planning technique
(ADePT): a dependency structure matrix tool to schedule the building design process, Construction Management and Economics, Vol. 18, 173-182.

[4] Baldwin, A. Austin, S. Hassan, A. Thorpe, A. (1999) Modeling information flow during the conceptual and schematic stages of building design, Construction Management and Economics, Vol. 17, 155-167.

[5] Cho, S. Eppinger, S. (2005) A simulation-based process model for management complex design project, IEEE Transactions on Engineering Management, EM Vol. 52, No. 3, 316-328.

[6] Wang, W. Liu, J. Liao, T. (2006) Modeling of design iterations through simulation, Automation in Construction, Vol. 15, 589-603.

[7] Rivard, S. Fenves, S. (2000) A representation for conceptual design of building, Journal of Computing in Civil Engineering, Vol. 14, No. 3, 151-159.

[8] Sanvido, V. Norton, K. (1994) Integrated design-process model, Journal of Management in Engineering, Vol. 10, No. 5, 55-62.

[9] Steward, D. (1981) The design structure system: a method for managing the design of complex systems, IEEE Transactions on Engineering Management, EM Vol. 78, No. 3, 71-74.

[10] Wang, W. Dzeng, R. (2005) Applying cluster identification algorithm and simulation to generate probabilistic network schedules for design projects, Construction Management and Economics, Vol. 23, No. 2, 199-213.

[11] Martinez, J. (1996) STROBOSCOPE: state and resource based simulation of construction Processes, PhD. Dissertation, University of Michigan, Ann Arbor, Michigan. 